\title{
The Interaction of the Deictic and Pragmatic Components in the Semantics of the Belarusian and English Possessive Pronouns: the Comparative Aspect
}

\author{
Artiomava Olga Alexandrovna ${ }^{1}$ \\ Associate professor, Minsk State Linguistic University, \\ Minsk, Belarus. \\ (date of receiving: January, 2018; date of acceptance: May, 2018)
}

\begin{abstract}
The article is devoted to the comparative analysis of Belarusian and English pronominal means of expressing personal deixis as one of the most important categories of communication, since an utterance cannot be produced without the indication to participants in speech interaction. Traditionally, personal and possessive pronouns are considered to be the key markers of this category in the language, as they connect the ontological (the nature of things) and situational (real speech situation) concepts together. However, due to their dual semantics, Belarusian and English possessions significantly expand the range of their functions from narrow, conventional ones, which are prescribed by the society and automatically used by the communicators, to additional pragmatic ones that allow regulating the speech interaction on the basis of intersubjective, personal and axiological oppositions. Thus, as a result, it helps the communicators achieve their goals through the strategy of cooperation with the tactics of establishing contact, integration, praise and sympathy and the confrontation strategy with tactics of threat, lowering the communicative status of the addressee and distancing.
\end{abstract}

Keywords: Deixis, Communicative Tactics and Strategy, Category of Possessiveness, Indication, Personal Deixis

1. E-mail: artimosha2008@rambler.ru 


\title{
Взаимодействие дейктического и прагматического компонентов в семантике белоруских и английских притяжательных местоимений: сопоставительный аспект
}

\section{Артемова Ольга Аллександровна ${ }^{1}$}

Доцент, Минский государственный лингвистический университет,

$$
\text { Минск, Республика Беларусь. }
$$

(дата получения: январь 2018 г.; дата принятия: май 2018 г.)

\begin{abstract}
Аннотация
Статья посвящена сопоставительному анализу белорусских и английских прономинальньх средств выражения персонального дейксиса как одной из наиболее важных категорий общения, поскольку высказывание не может быть продуцировано без указания на участников речевого взаимодействия. Традиционно личные и притяжательные местоимения считаются ключевыми маркерами этой категории в языке, поскольку они связывают онтологическую (природа вещей) и ситуационную (конкретная речевая ситуация) концепции вместе. Однако, обладая двойственной семантикой, белорусские и английские посессивы значительно расширяют диапазон своих функций от узких, конвенциональных, являющцися предписанием социума и используемых коммуникантами автоматически, до дополнительных прагматических, позволяющих регулировать речевую интеракцию носителей данных языков на основе трех типов оппозиций: интерсубъектной (свой - чужой), личностной (свой - не свой) и аксиологической (правильно - неправильно) оппозиций, что, в результате, способствует достижению коммуникантами своих целей посредством стратегии сотрудничества с тактиками установления контакта, интеграции, похвалы и симпатии, и стратегии конфронтации с тактиками угрозы, понижения коммуникативного статуса адресата и дистанцирования.
\end{abstract}

Ключевые слова: Дейксис, Коммуникативная Тактика И Стратегия, Категория Посессивности, Указание, Персональный Дейксис.

1. E-mail: artimosha2008@rambler.ru 


\section{Введение}

Категория дейксиса относится к важнейшим категориям языковой коммуникации, поскольку высказывание не может быть реализовано вне указания на пространство и время. Ядерными средствами актуализации персонального дейксиса, наряду с личными местоимениями, выступают и притяжательные местоимения, относящиеся к корпусу языковых маркеров категории поссесивности, основу которой, по мнению А.Е. Кибрика, составляет «абстрактное отношение когнитивной сопряженности, связывающее два концепта онтологически (по природе вещей) или ситуационно (в конкретной актуализованной ситуации)» (Кибрик 2004. 265), когда говорящему нужен более заметный, когнитивно выпуклый (salient) ориентир (reference point) для локализации объекта путем соотнесения с этим ориентиром - посессором «для лучшей идентификации искомого референта» (Вайс 2004. 283).

Притяжательные местоимения до сих пор являются предметом лингвистических дискуссий. Некоторые исследователи ставят под вопрос само выделение этих слов в отдельный лексико-грамматический класс (Шахматов 2001. 495) или рассматривают посессивы как подкласс личных местоимений (Исаченко 1968. 180). Мы, вслед за Б.Ю. Норманом, выделяем посессивы в отдельный разряд местоименных слов, семантически соотносящихся с личными местоимениями, но обладающих спектром отличительных прагматических характеристик (Норман 1999. 616).

\section{Основная часть}

Система современного белорусского языка включает 9 притяжательных местоимений: мой, наш, твой, ващ, яго, ягоны, ейны, іхні, свой. Английскому языку свойственно наличие двух типов местоименных посессивов: относительные (my, your, his, her, its, our, their) и абсолютные (mine, yours, his, 
hers, its, ours, theirs). Несмотря на то, что посессивный компонент является основным в структуре значения этой группы слов, они очень редко (по некоторым подсчетам, лишь в 5 \% случаев) обозначают обладание как таковое (Норман 2009. 63). Как правило, они передают идею принадлежности через указание на границы личной сферы коммуникантов, под которой понимается ментальное пространство, куда «входит говорящий и все, что ему близко физически, морально, эмоционально или интеллектуально» (Апресян 1986. 28). Эта особенность категоризации действительности находит отражение в семантике притяжательных местоимений, характеризующиеся совмещением дейктических и назывных сем. Такая двойственность семантики этой группы слов значительно расширяет сферу их прагматических функций от традиционных, конвенциональных, являющихся предписанием социума и используемых коммуникантами автоматически (клише, типовые схемы словосочетаний, синтаксические конструкции и общие модели речевого поведения в конкретных ситуациях: ичьра Bau, faithfully yours) до дополнительных прагматических функций, которые позволяют регулировать речевую интеракцию на основе трех типов оппозиций:

1) интерсубъектной, когда речевое поведение адресанта выстраивается на основе включения / невключения адресата в личную сферу говоряшего (свой / чужой) с актуализацией прагмасмыслов солидарности или отчуждения через поляризацию интересов коммуникантов;

2) личностной, когда субъект речи задает тональность общения и демонстрирует расположение к адресату с актуализацией прагмасмыслов доверия, симпатии или отстраненности;

3) аксиологической, когда речевое взаимодействие участников коммуникации регулируется системой оценочных установок личности (правильно / неправильно, одобряемо / неодобряемо, допустимо / недопустимо и т.П.). 
Эти семантико-когнитивные оппозиции формируют основу речевых стратегий коммуникантов, представляющих собой комплекс речевых действий, направленных на достижение определенных целей. К понятию стратегии, впервые использованному исследователями Т.А. ван Дейком и У. Кинчем для анализа дискурса (Дейк, Кинч, 1983), обращались многие лингвисты. $\mathrm{K}$ настоящему времени сложились две наиболее распространенные концепции стратегии как:

а) плана, канвы, типа поведения, определяющих последовательность выбора речевых действий и языковых средств в работах В.С. Кашкина, Т.А. Дейка и В. Кинча, М.Л. Макарова, В.С. Третьяковой;

б) совокупности практических ходов для достижения коммуникативной цели в процессе речевого взаимодействия в работах Б.В. Клюева и Т.В. Матвеевой. С нашей точки зрения, эти две концепции отражают дуалистичную сущность коммуникативной стратегии, которой свойственны ригидность и пластичность. Ригидность выражается в конвенциональности речевого поведения участников интеракции в типичных коммуникативных ситуациях. Пластичность стратегии проявляется в ее наделении говорящего способностью эвристично контролировать решение комплекса задач в рамках цели с определением наиболее приоритетных интенциональных установок и обеспечении возможности их реализации широким спектром разнообразных тактик и приемов при помощи разноуровневых языковых ресурсов в коммуникативных ситуациях, многообразие которых объясняет отсутствие в современной прагмалингвистике исчерпывающей классификации коммуникативных стратегий. Основанием построения такой классификации может выступать:

1) типология целевых установок участников интеракции, направленных на а) изменение компонентов коммуникативной ситуации (регулятивная стратегия), б) осведомление собеседника о фактах и событиях 
действительности (диктальная стратегия); в) выражение чувств, эмоций и оценки (модальная стратегия) (Борисова, 2009);

2) степень глобальности коммуникативных целей, варьируемая от локальной коммуникативной задачи в конкретной речевой ситуации, решаемой частными стратегиями, до неограниченных рамками конкретной коммуникативной ситуации целей, реализуемыми общими (когнитивносемантическими) стратегиями, подразделяющимися на основные и вспомогательные. Основные стратегии контролируют достижение главной цели речевой интеракции. Вспомогательные стратегии способствуют результативной организации речевого взаимодействия посредством коммуникативноситуационных (автор, адресат, канал связи, коммуникативный контекст), диалоговых (мониторинг темы и степени понимания) и риторических (эффективное воздействие на адресата) стратегий (Иссерс 2008. 104-109);

3) результат речевой интеракции, соотносящийся с двумя глобальными принципами общения - принципом кооперации и принципом соперничества (конфронтации), в основе которых, по мнению исследователя И. Гоффмана, лежат два основополагающих для каждого индивидуума мотива: защита от вторжения на свою личностную территорию и установление связи с себе подобными (Гофман 1987. 44). Оба этих мотива взаимодействуют в процессе речевой интеракции, когда говорящий, вступая в коммуникацию, вынужден вторгаться на территорию собеседника и одновременно сохранять свое лицо. Для кооперативного речевого поведения характерны тактики интеграции, солидаризации, интимизации, способствующие повышению статуса адресата и созданию конструктивной атмосферы общения. Конфронтационное речевое поведение организуется тактиками доминирования адресанта и понижения коммуникативного статуса собеседника для создания деструктивной тональности общения и ответной отрицательной эмоциональной и поведенческой реакции адресата. 
Промежуточное положение между стратегиями кооперации и конфронтации занимает стратегия негативной вежливости как набор конвенциональных тактик, минимизирующих прямое воздействие на адресата и способствующих его социальному дистанцированию с созданием коммуникативных барьеров между собеседниками (Браун, Левинсон. 1978).

Стратегия реализуется посредством одной или нескольких тактик, обладающих динамическим характером и обеспечивающих ее гибкость. В качестве инструмента реализации тактики выступают коммуникативные приемы более низкого порядка - коммуникативные (речевые) ходы. Рассмотрим функции белорусских и английских притяжательных местоимений в реализации коммуникативных тактик и стратегий носителей эТИХ язЫков.

Притяжательные местоимения 1-го лица ед.ч. мой и my, осуществляя указание на адресанта, в сочетании с именем адресата способствуют сближению говорящего и слушателя с включением последнего в личностную сферу субъекта речи через тактику интеграции: - Братка ты м мой! Хоць mы $i$ тамцюр цара нябеснага, а $я$ иябе люблю, дальбог, люблю... (НКРЯ); "Ah, my cherished! cried The Vengeance; and embraced her (C. Dickens. The Tale of two Cities) 'Бесценная ты моя! - взвизгнула Месть и бросилась ей на шею’ (НКРЯ). Обращения, построенные по модели суцествительное / прилагательное $+m b+$ мой, используются как дополнительное средство идентификации и характеризации адресата, где существительные или прилагательные занимают прагматически сильную позицию и актуализируют положительное отношение говорящего к собеседнику: Дружыначка ж ты мая, наито ж ты мяне ... пакідаеи? (У. Караткевіч. Каласы пад сярпом тваім) (HKPЯ); «My ducky, it's only just eleven now» (J. Galsworthy. Awakening) (НКРЯ) '- Милый ты мой, сейчас только одиннадцать часов'. В таких случаях, по мнению Н.Д. Арутюновой, поссессивное местоимение 
осуществляет указание именно на субъект оценки (“для меня ты милая/дорогая') (Арутюнова 1998. 116). По мнению Е.М. Вольф, такое прагматическое значение «хороший, положительный» у поссесивных местоимений 1-го лица, указывает на их связь с оценкой и их аксиологической дистрибуцией, где зона 1-го лица соотносится «с положительной частью оценочной шкалы или смягчает отрицательную оценку», а зона 2-го лица - «с отрицательной» (Вольф 1985. 180). Этой особенностью обусловлено употребление дательного этического Dativus ethicus для экспликации желания говорящего присвоить себе самое лучшее, и тогда нейтральная грамматическая метка мой становится выражением наивысшей оценки (Цивьян 1983. 116).

Белорусский посессив 1-го лица мн. ч. наш в отличие от его английских эквивалентов our, ours является наиболее нагруженным в культурном отношении, что связано не только с историческим наследием советской идеологии, но и с семантическим наполнением 1-го лица мн.ч. как совокупного, «корпоративного». Современный прагмасмысл поссесива наи 'правильный, уместный, верный в данном социуме' отличается от своего узкого первоначального значения 'родной, близкий' своей идеологизированностью и маштабностью. Несмотря на то, что местоимение наи указывает на множественность субъектов, этот поссессив часто обозначает говорящего, который, отождествляя себя с данным коллективом, разделяет установленные в этом сообществе правила и обязанности и оценивает их положительно, что обусловливает их употребление говорящим для реализации тактики интеграции: - Справа, браце, у тым, што, як кажуць, не звяліся яичэ багатыры на нашай зямлі. Нас пазвальнялі, а вось знайцліся паміж нашаю братвою людзі, аб якіх мы нічога не ведаем і якія не мірацца з нашым звальненнем, заступаюџца за нас, пратэстуюць. I наша справа такім чьънам набывае пэўны водгук (Я. Колас. На ростанях) (НКРЯ); Despite our 
hardships, our union is strong. We do not give up. We do not quit (Обама, 2010) 'Несмотря на наши трудности, наш союз крепок. Мы не уступаем. Мы не сдаемся'

Притяжательные местоимения в этой функции выступают как способ реализации категории детерминации, передавая общее концептуальное содержание взаимодействия и связи конкретного лица с окружающим миром. Отсюда возможность использования местоимений мой, my и наш, our в фатической функции как установления контакта с адресатом с реализацией максимам такта, скромности и симпатии: Добры дзень, мае маноўныя сябры! (Мая прыгожая Беларусь); Hello dear viewers! (Sorastro. Sorastro's painting) 'Здравствуйте, дорогие зрители!'

В противоположность 1-му лицу посессив 2-го лица зачастую характеризуется пейоративностью семантики $\mathrm{c}$ реализацией тактики отчуждения. Однако во многих случаях это не просто отрицательная семантика, но и скрытая цитация, отсылка к адресату с передачей его мнения и манерой говорить, темы, среды: - Ну як жа не любіуь яе? - вырвалася у яго. -A гэтым пытаннем хай твой Гамэр мучаециа. Лепи бы ажаніуся (В. Чаропка. Адрачэнне ад цемры) (НКРЯ); Сацыялізм ваш здох, хіба ня бачьце! Ад яго на cъвеце смурод (В. Быкаў. Труба) (НКРЯ); My auntie "... "Sucks to your auntie"! Ralph did a surface dive and swam under waterwith his eyes open; the sandy edge of the pool loomed up like a hillside (W. Golding. Lord of the Flies) 'Моя тетя... 'Слыхали про твою тетю! Ральф нырнул и поплыл под водой соткрытыми глазами: песчаный край бухты маячил, как горный кряж’ (НКРЯ).

На наш взгляд, такой разнополярность прагматических значений посессивных конструкций с притяжательными местоимениями 1-го и 2-го лиц объясняется выделенностью адресанта и адресата как ориентиров в коммуникативной ситуации. В этом плане интересно наблюдение А. Вежбицкой о грамматикализации многими индоевропейскими языками 
плохого или хорошего события посессивными конструкциями, например с Dativus Ethicus, включающими эмоционально воспринимающего события «поссесора» (Вежбицка 1979. 357-360).

Особую роль в белорусском языке выполняет поссесивная конструкция $y+G e n$. Употребление такой конструкции направлена на оказание воздействия на адресата под влиянием фактора субъективации как стремлении языковых единиц отражать не только действительность, но и отношение говорящего к ней. В белорусском языке конструкция у мяне / у нас служит для реализации тактик

1) похвалы: - А якая ж ты уу мяне стала зграбная, прыгожая! (У. Караткевіч. Дзікае паляванне караля) (НКРЯ);

2) сочувствия и интимизации с актулизацией заинтересованности в субъекте оценки: - Tы й мяне адзін астаўся, з усёй нашай сям'i (К. Чорны. Семнаццаць год) (НКРЯ);

3) угрозы: - Цяпер ты уимяне сядзеи, - сплюнуу у сметніиу Патапейка... (У. Някляеў. Лабух) (НКРЯ).

Подобный прагматический эффект возникает в результате употребления эмоционально-оценочной лексики, для которой, по мнению В.И. Жельвиса, «возможно противоречивое смешение в одном употреблении $<\ldots>$ отрицательно заряженного качества и положительного свойства, и наоборот» (Жельвис 1990. 90), вызванного двойственностью передаваемого эмоционального состояния, которое «неизбежно приводит к амбивалентному восприятию слова» (Жельвис 1990. 90).

В сочетании с именами собственными ваи и твой могу приобретать качественно-оценочные признаки для реализации тактик

1) порицания: Антон нецярпліва рэзка усстаў з лаўкі $i$, сагнуўиы галаву пад нізкаю столлю, зірнуу праз няичыльна прычыненыя дзверы, з якіх усё несла ветрам і сиюжсай. - Hу, дзе ж твой Барматухін? (В. Быкаў. Пайсці і не вярнуцца) (НКРЯ); 
2) понижения коммуникативного статуса референта в фразеологизированных сочетаниях типа ваи брат: Мне будзе лягчэй, чыл ванаму брату, бо я ўжо сутыкаўся з забойцам $і$ у адным сваім жыџиі, $і$ у другім (У. Мажылоўскі. Тайна гіблай затокі) (НКРЯ).

Формальная структура белорусских притяжательных местоимений 1-го лица мой, наш и 2-го лица твой, ваш сходна, поэтому они легко рифмуются, что фиксируется многочисленными поговорками и пословицами $I$ нашым $i$

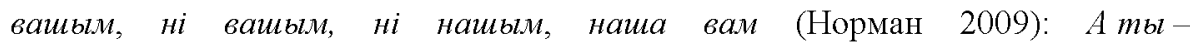
і нашылм, і вашылм. - Я ня вашым... (В. Быкаў. Жоўты пясочак) (НКРЯ).

Поссесивы 3-го лица яго, яе, ix (ixнi), his, her, hers, their, theirs традиционно указывают на некоммуникативных лиц, которые не являются непосредственными участниками речевого акта и используются участниками коммуникации для реализации тактик дистанцирования и сопоставительного анализа через оппозицию притяжательных местоимений 1-го и 3-го лица множественного числа или указательных местоимений тое, тая, mоe, mыл, that, those: - $Я$ вам кажу. I вы лепей не на иаш разумны гуманізм навальвайцеся, а на тыхх, хто труціць азёры, рэкі, лясы, хто не сёння-заутра атруиіџь акіяны. $\mathbf{M ы ~ - ~ у с е ̈ ~ д л я ~ у ̆ н у к а у ̆ , ~ х а и я ~ р у к і ~ у ̆ ~ н а с ~ ч а с а м ~ б ы в а ю и ь ~ у ~ к р ы в і . ~}$ У mых - усё для кішэні і пуза, а рукі чысиенькія (У. Караткевіч. Чазенія) (НКРЯ); They [terrorists] act out of hatred; we don't seek revenge, we seek justice out of love." (Буш, 2001) 'Они [террористы] действуют из ненависти; мы не ищем мести, мы ищем справедливости из-за любви'.

Реализация прагматических категорий зависит от частоты и облигаторности употребления посессива в данном языке. Как показал анализ фактического материала, там, где в английском языке притяжательное местоимение для выражения принадлежности как указания на обладателя обязательно присутствуют (особенно с существительными, обозначающими части тела, членов семьи, одежду), в белорусском языке экспликация этих 
отношений необязательна: "Professor Langdon?" A male student in back raised his hand, sounding hopeful (D. Brown. The Da Vinci Code) [HKPЯ] - Пpoфeccop Лэнгдон? - Какой-то паренек поднял руку и с надеждой смотрел на преподавателя'; Васіль падняу руку і стрэліу - mуды, на пагонку, панёсся nагрозны (Г. Далідовіч. Жывы покліч) (НКРЯ). В белорусском языке употребление притяжательных местоимений с существительными, обозначающими части тела, членов семьи, одежду придает высказыванию дополнительные прагматические коннотации: Давай дамовімся, дружа. Вось табе мая рука. Төой Віктар (М. Стральцоў. Сена на асфальце) (НКРЯ). Данное наблюдение позволяет сделать предположение о факультативном характере ориентации на говорящего субъекта в белорусском языке в отличие от английского языка, где эта ориентация обязательна. Это связано с тем, что категория притяжательности и категория детерминации в белорусском языке не имеет грамматического статуса, в то время как в английском языке эти две категории тесно связаны между собой и требуют обязательного эксплицитного выражения: I stuck out my hand and wondered what he wanted (L. Weisberger. The Devil Wears Prada) '- Я протянула ему руку, мне было интересно, чего он от меня хочет' (НКРЯ). В белорусском языке в подобных контекстах притяжательные местоимения опускаются либо заменяются на поссесив свой, аккумулирующий в себе прагмасмыслы всех трех лиц от свой «со знаком плюс», где оно эмфатично и находится в ударной, рематической позиции (Amкрой, мамама. Сваі (В. Быкаў. Знак бяды) (НКРЯ) до неударного свой, сваi «са знаком минус» (- Ты проста жыция не даеи людзям сваімі допытамі (I. Шамякін. Крыніцы) (НКРЯ); Але, відаць, гэта нялёгка зразумець, ито раиэнне такое патрэбна не толькі польскаму народу, але і нам, расіянам, тым «асветнікам», якія хочуць пакласці у сваю кішэню чужое, і уссім іниым, хто адурманены вялікадзяржаўным чадам (І. Шамякін. Петраград-Брэст) (НКРЯ). Эта особенность находит свое отражение и в белорусской 
фразеологии, где притяжательное местоимение свой часто передает значение 'собственный' свая камуля бліжэй да цела 'своя рубашка ближе телу' (*Мая, твая, яго кашуля бліжэй да цела), свая сярмяжка не важка 'своя ноша не тянет' (*Мая, твая, яго сярмяжка не важка).

\section{Заключение}

Таким образом, белорусские и английские притяжательные местоимения, наряду с осуществлением указания на участников коммуникации - адресата и адресанта, позволяют реализовать им свои цели посредством стратегии кооперации с тактиками установления контакта, интеграции, похвалы, сочувствия и интимизации и конфронтации с тактиками угрозы, порицания, понижения коммуникативного статуса референта и дистанцирования.

\section{Литература}

1- Апресян Ю.Д. (1986). Дейксис в лексике и грамматике и наивная модель мира. Семиотика и информатика. М., Вып. 28. С. 5-33.

2- Арутюнова Н.Д. (1998). Язык и мир человека, Москва, Изд-во «Языки славянской культуры».

3- Борисова И.Н. (2009). Русский разговорный диалог: СТруктура и динамика. Москва, Изд-во «Либроком».

4- Браун, П., Левинсон, С. (1978). Вежливость: некоторые универсалии в употреблении языка. Cambridge; New York: Cambridge University Press.

5- Буш, Д. (2001). Вы либо с нами, либо с террористами / Голос Америки [Электронный pecypc]. - Режим доступа: http://www.voanews.com/content/a-13a-2001-09-21-14-bush-66411197/549664.html. Дата доступа: 4.03.2016.

6- Вайс Д. (2004). Смысловой потенциал поссесивного отномения и его текстуальная обусловленность в современном русском языке. Сокровенные смыслы. Слово. Текет. Культура. Сборник статей в честь Н. Д. Арутюновой. Москва, Изд-во «Языки славянской культуры».

7- Вежбицка, А. (1979). Этносинтаксис и философия грамматики. Studies in Language, 3(3). Amsterdam: John Benjamins.

8- Вольф Е.М. (1985). Функциональная семантика оиенки. Москва, Издво «Наука». 
9- Гоффман, И. (1987). Фигуры речи. Paris: Minuit.

10- Дейк, Т.А, Кинч, В. (1983). Стратегии понимания связного текста. New York: Academic Press.

11- Жельвис В.И. (1990). Эмотивный аспект речи. Психолингвистическая интер претация речевого воздействия. Ярославль, Изд-во «ЯГТГИ им. К.Д. Ушинского».

12- Исаченко, А.В. (1968). Современный русский язык. Max Niemeyer Verlag. Teil I. Formenlehre.

13- Иссерс О.С. (2008). Коммуникативные стратегии и тактики русской речи. Москва, Изд-во «ЛКИ».

14- Кибрик А.Е. (2004). Опьт фронтального корпусного исследования конструкций $c$ внутренним и внеиним посессором. Компьютерная лингвистика и интеллектуальные технологии: Труды международной конференции Диалог'2004. Москва, «Изд-во Наука», 2004.

15- Мая прыгожая Беларусь (Электронный ресурс). Режим доступа: oll.stolin.edu.by $/ \mathrm{m} / \mathrm{main}$.aspx?guid $=21303$

16- НКРЯ - Национальный корпус русского языка (Электронный ресурс). Режим доступа:http://www.ruscorpora.ru.

17- Норман Б.Ю (1999). О притяжсательных местоимениях в славянских языках. Slavia Orientalis. Polska Akademia Nauk, Wydziai Nauk Spotecznych, Komitet Slowianoznawstwa. Krak6w: Bohdan Grell і сбгка, T. XLVIII, Kraków: Bohdan Grell i córka.

18- Норман Б.Ю. (2009). Лингвистическая прагматика (на материале русского и других славянских языков): курс лекций. Минск, Изд-во «БГУ».

19- Обама Б. (2010). Замечания Президента к Речи послания к Конгрессу (Электронный ресурс)- Режим доступа: http:// whitehouse ...https://obamawhitehouse.archives.gov/the.../remarks-preside... Дата доступа: 23.04.2017.

20- Copacmpo. Картина Copacmpo. (Электронный ресурс). Режим доступа: https://sorastro.com/author/mrsorastro. Дата доступа : 23.05.2016.

21- Цивьян Т.В. (1983). Об одном особом аспекте посессивности: Dath. eth. и его трансформы (на материале балканских языков). Категория притяжательности в славянских и балканских языках. Тезисы совещания. Москва Изд-во «ИСБ $\mathrm{AH} \mathrm{CCCP} \gg$.

22- Шахматов А.А. (2001). Синтаксис русского языка. Москва, Изд-во «Эдиториал». 


\section{Bibliography}

1- Apresjan Ju.D. (1986). Dejksis v leksike i grammatike i naivnaja model' mira. Semiotika i informatika. M., Vyp. 28. S. 5-33.

2- Arutjunova N.D. (1998). Jazyk i mir cheloveka, Moskva, Izd-vo «Jazyki slavjanskoj kul'tury».

3- Borisova I.N. (2009). Russkij razgovornyj dialog: Struktura i dinamika. Moskva, Izd-vo «Librokom».

4- Braun, P., Levinson, S. (1978). Vezhlivost': nekotorye universalii v upotreblenii jazyka. Cambridge; New York: Cambridge University Press.

5- Bush, D. (2001). Vy libo s nami, libo s terroristami / Golos Ameriki [Jelektronnyj resurs]. - Rezhim dostupa: http://www.voanews.com/content/a-13-a-2001-09-2114-bush-66411197/549664.html. Data dostupa: 4.03.2016

6- Vajs D. (2004). Smyslovoj potencial possesivnogo otnoshenija i ego tekstual'naja obuslovlennost' $\mathrm{v}$ sovremennom russkom jazyke. Sokrovennye smysly. Slovo. Tekst. Kul'tura. Sbornik statej v chest' N. D. Arutjunovoj. Moskva, Izd-vo «Jazyki slavjanskoj kul'tury».

7- Vezhbicka, A. (1979). Jetnosintaksis i filosofija grammatiki. Studies in Language, 3(3). Amsterdam: John Benjamins.

8- Vol'f E.M. (1985). Funkcional'naja semantika ocenki. Moskva, Izd-vo «Nauka».

9- Goffman, I. (1987). Figury rechi. Paris: Minuit.

10- Dejk, T.A, Kinch, V. (1983). Strategii ponimanija svjaznogo teksta. New York: Academic Press.

11- Zhel'vis V.I. (1990). Jemotivnyj aspekt rechi. Psiholingvisticheskaja interpretacija rechevogo vozdejstvija. Jaroslavl', Izd-vo «JaGTGI im. K.D. Ushinskogo».

12- Isachenko, A.V. (1968). Sovremennyj russkij jazyk. Max Niemeyer Verlag. Teil I. Formenlehre.

13- Issers O.S. (2008). Kommunikativnye strategii i taktiki russkoj rechi. Moskva, Izdvo «LKI».

14- Kibrik A.E. (2004). Opyt frontal'nogo korpusnogo issledovanija konstrukcij s vnutrennim $i$ vneshnim posessorom. Komp'juternaja lingvistika i intellektual'nye tehnologii: Trudy mezhdunarodnoj konferencii Dialog'2004. Moskva, «Izd-vo Nauka», 2004.

15- Maja prygozhaja Belarus' (Jelektronnyj resurs). Rezhim dostupa: oll. stolin.edu.by $/ \mathrm{m} / \mathrm{main}$.aspx?guid $=21303$

16- NKRJa - Nacional'nyj korpus russkogo jazyka (Jelektronnyj resurs). Rezhim dostupa: http:// www. ruscorpora.ru. 
17- Norman B.Ju (1999). O pritjazhatel'nyh mestoimenijah v slavjanskih jazykah. Slavia Orientalis. Polska Akademia Nauk, Wydziai Nauk Spotecznych, Komitet Slowianoznawstwa. Krak6w: Bohdan Grell i sbgka, T. XLVIII, Kraków: Bohdan Grell i córka.

18- Norman B.Ju. (2009). Lingvisticheskaja pragmatika (na materiale russkogo i drugih slavjanskih jazykov): kurs lekeij. Minsk, Izd-vo «BGU».

19- Obama, B. (2010). Zamechanija Prezidenta $k$ Rechi poslanija $k$ Kongressu (Jelektronnyj resurs) - Rezhim dostupa: http:// whitehouse ...https://obamawhitehouse.archives.gov/the.../remarks-preside... Data dostupa: 23.04 .2017

20- Sorastro. Kartina Sorastro. (Jelektronnyj resurs). Rezhim dostupa: https://sorastro.com/author/mrsorastro. Data dostupa : 23.05.2016.

21- Civ'jan T.V. (1983). Ob odnom osobom aspekte posessivnosti: Dath. eth. i ego transformy (na materiale balkanskih jazykov). Kategorija pritjazhatel'nosti $\mathrm{v}$ slavjanskih i balkanskih jazykah. Tezisy soveshhanija. Moskva Izd-vo «ISB AN SSSR).

22- Shahmatov A.A. (2001). Sintaksis russkogo jazyka. Moskva, Izd-vo «Jeditorial».

\section{HOW TO CITE THIS ARTICLE}

Artiomava Olga Alexandrovna (2018). The Interaction of the Deictic and Pragmatic Components in the Semantics of the Belarusian and English Possessive Pronouns: the Comparative Aspect . Issledovatel'skiy zhurnal russkogo yazyka i literatury. 12(2):pp:71-86

DOI: $10.29252 /$ iarll. 12.51

URL: http://journaliarll.ir/article-1-143-en.html

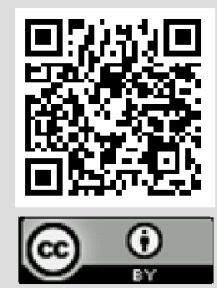




\title{
بررسى تعامل و ارتباط عناصر شيئيت و كاربردشناسى معنى و مفهوم ضميرهاى مالكيت در زبانهاى بلاروسى و انكليسى: مطالعه تطبيقى
}

\author{
اولكا الكساندروونا آرثيومووا' \\ دانشيار دانشخاه دولتى زبانشناسى مينسك، \\ مينسك، بلاروس.

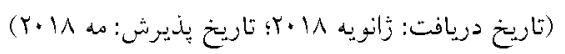

اين مقاله به تجزيه و تحليل مقايسهاى ابزارهاى كلامى بيان ضمير در زبانهاى بلازوسى و و

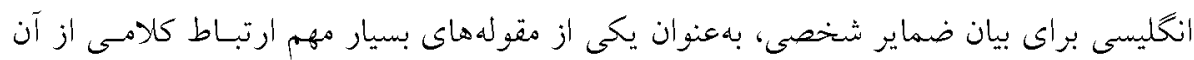

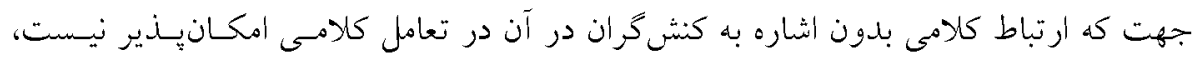

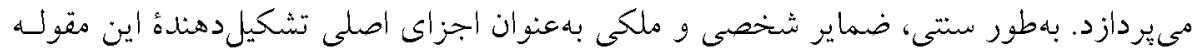

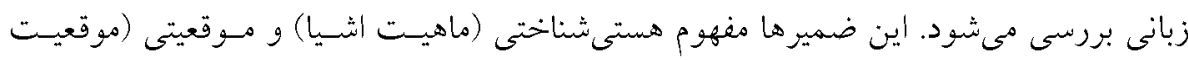

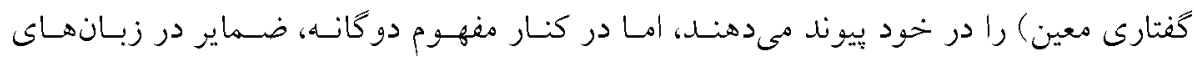

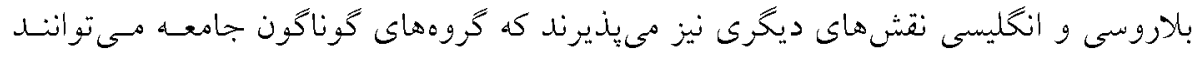

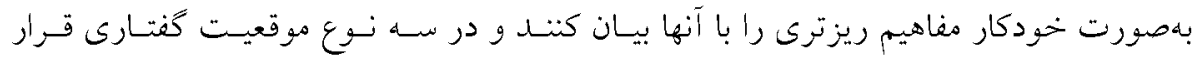

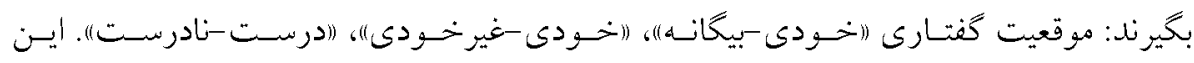

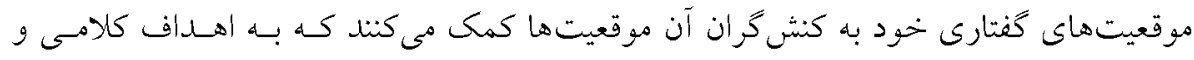

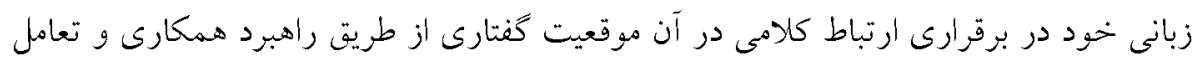

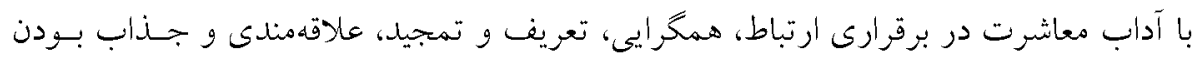

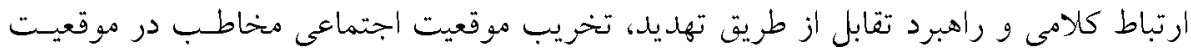
كفتارى و ايجاد فاصله در آن برسند.

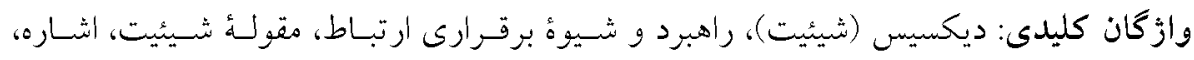

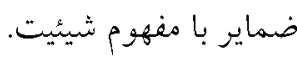

1. E-mail: artimosha2008@rambler.ru 